\title{
Plantes pesticides et protection des cultures maraichères en Afrique de l'Ouest (synthèse bibliographique)
}

\author{
Boni Barthélémy Yarou ${ }^{(1)}$, Pierre Silvie ${ }^{(2,3)}$, Françoise Assogba Komlan ${ }^{(4)}$, \\ Armel Mensah ${ }^{(4)}$, Taofic Alabi ${ }^{(1)}$, François Verheggen ${ }^{(1)}$, Frédéric Francis ${ }^{(1)}$ \\ (1) Univ. Liège - Gembloux Agro-Bio Tech. Département AgroBiochem. Entomologie fonctionnelle et évolutive. Passage des \\ Déportés, 2. BE-5030 Gembloux (Belgique).E-mail : boniyarou1981@gmail.com ; entomologie.gembloux@ulg.ac.be \\ (2) Université Paris-Saclay. Laboratoire EGCE. UMR IRD. CNRS. FR-91198 Gif-sur-Yvette Cedex (France). \\ (3) CIRAD. UPR Agroécologie et Intensification Durable des cultures Annuelles. FR-34398 Montpellier Cedex 5 (France). \\ (4) Institut National des Recherches Agricoles du Bénin. Programme Cultures Maraichères. 01 BP 884 Recette Principale. \\ Cotonou (Bénin).
}

Reçu le 2 mars 2017, accepté le 5 septembre 2017, mis en ligne le 22 septembre 2017.

Cet article est distribué suivant les termes et les conditions de la licence CC-BY (http://creativecommons.org/licenses/by/4.0/ deed.fr)

Introduction. Les cultures maraichères occupent une place importante pour l'alimentation humaine et contribuent significativement aux revenus des familles en Afrique de l'Ouest, mais leur production est confrontée à une pression des bioagresseurs qui limite leur productivité.

Littérature. Cette revue, basée sur des publications scientifiques, a pour objectif d'évaluer le potentiel des plantes pesticides comme alternative à l'usage des pesticides de synthèse pour lutter contre les bioagresseurs des cultures maraichères en Afrique de l'Ouest. Elle montre que le principal moyen actuel pour combattre ces bioagresseurs repose essentiellement sur les pesticides de synthèse. Cependant, compte tenu de leur nocivité sur l'homme et l'environnement, en plus de la sélection de populations résistantes chez les bioagresseurs, la recherche de solutions alternatives s'impose. Les plantes pesticides se présentent comme une alternative prometteuse dans le contexte ouest-africain. En effet, diverses espèces de plantes pesticides peuvent être utilisées comme extraits de plantes ou en association avec d'autres cultures pour le contrôle des bioagresseurs. Celles-ci sont présentées dans le présent article de synthèse.

Conclusions. Les plantes pesticides peuvent être une alternative prometteuse pour la gestion des bioagresseurs des cultures maraichères. Cependant, la plupart d'entre elles ne sont pas cultivées. Explorer les capacités biocides de plantes d'intérêt comme le genre Ocimum, connu pour ses usages thérapeutique, médicinal et alimentaire pourrait être intéressant pour le producteur. Toutefois, les populations doivent être sensibilisées sur les avantages à long terme des produits traités avec les pesticides à base de plantes pour faciliter leur utilisation.

Mots-clés. Plante pesticide, extrait d'origine végétale, culture maraichère, lutte antiravageur, Afrique au Sud du Sahara.

\section{Pesticidal plants and vegetable crop protection in West Africa. A review}

Introduction. Vegetable crops play a leading role in human nutrition and contribute significantly to the incomes of families in West Africa. However, their production is hampered by pressure from pests, which limits their productivity.

Literature. This review, based on scientific publications, aims to evaluate the potential of pesticidal plants as an alternative to the use of synthetic pesticides to control vegetable crop pests in West Africa. It shows that the primary current method used to control these pests is mainly based on synthetic pesticides. However, in view of their harmful effects on humans and the environment, in addition to the range of resistant pest populations, the search for alternative approaches is needed. Pesticidal plants are a promising alternative in the West African context. Indeed, various species of pesticidal plant can be used as plant extracts or in association with other crops in pest management. These plants are presented in this review article.

Conclusions. Pesticidal plants can be a promising alternative for the pest management of vegetable crops. However, most of these pesticidal plants are uncultivated. Exploring the biocidal capacities of these interesting plants, such as the genus Ocimum, known for its therapeutic, medicinal and food uses, could be of interest for farmers. However, populations need to be made informed of the long-term benefits of products treated with pesticidal plant extract, in order to facilitate their use.

Keywords. Pesticide crops, plant extracts, vegetable growing, pest control, Africa South of Sahara. 


\section{INTRODUCTION}

L'agriculture est l'un des principaux secteurs d'activités qui contribue au développement socioéconomique des populations. Elle emploie plus de $40 \%$ de la population active dans le monde, dont plus de $52 \%$ en Afrique et en Asie (MOMAGRI, 2016). Dans ce secteur, le maraichage occupe une place importante pour l'alimentation humaine (FAO, 2012). Défini comme une agriculture fortement spécialisée, le maraichage constitue l'un des systèmes agricoles les plus productifs d'Afrique (FAO, 2012). En Afrique de l'Ouest, il apparait comme l'une des composantes principales de l'agriculture urbaine et périurbaine ayant une importance capitale dans le développement économique des villes (FAO, 2012). Considérées comme une activité de souveraineté alimentaire (FAO, 2012), les cultures maraichères jouent un rôle primordial dans la plupart des programmes de nutrition, de lutte contre la pauvreté et contribuent significativement aux revenus des familles (James et al., 2010 ; Yolou et al., 2015). Cependant, la production de ces légumes est limitée par de multiples contraintes abiotiques et biotiques qui affectent les rendements et les opérations post-récoltes qui en découlent. La pression des bioagresseurs a été identifiée comme la contrainte majeure du fait des pertes de récoltes infligées aux maraichers (Kanda et al., 2014 ; Mondédji et al., 2015). Ainsi, pour améliorer les rendements et répondre à la demande des marchés sans cesse croissante, le recours à l'usage des pesticides de synthèse par les producteurs est quasiment systématique (Kanda et al., 2013 ; Mondédji et al., 2015). Pourtant, leurs effets néfastes sur l'homme et l'environnement et la résistance des bioagresseurs aux insecticides ont été démontrés (Assogba-Komlan et al., 2007 ; Houndété et al., 2010 ; Mondédji et al., 2015 ; Agboyi et al., 2016).

La combinaison de certaines pratiques agricoles comme la rotation des cultures, la protection physique (filets anti-insectes), l'utilisation des plantes pesticides (toute plante dont les propriétés chimiques peuvent être exploitées pour lutter contre les organismes considérés comme nuisibles) sont susceptibles de réduire significativement la pression des bioagresseurs et le besoin en pesticides de synthèse (Amoatey \& Acquah, 2010).

Les effets des plantes pesticides sur la dynamique des populations de ravageurs dans les cultures maraichères sont investigués dans cette revue qui se propose :

- de mettre en relation la diversité des spéculations maraichères aux bioagresseurs associés,

- de discuter la problématique des pesticides de synthèse comme principale méthode de lutte contre les ravageurs,
- de révéler l'importance des plantes pesticides comme une alternative pour la protection des cultures maraichères en Afrique de l'Ouest,

- de discuter les avantages et les limites liés à l'usage de ces plantes pesticides.

Cette synthèse invite à une réflexion globale sur les systèmes culturaux en Afrique de l'Ouest et constitue indubitablement une solide base scientifique pour assoir des programmes de recherche durable et écologique en vue de limiter l'incidence des bioagresseurs des cultures maraichères en Afrique de l'Ouest.

Les bases de données bibliographiques (Collection ULg, CAB Abstracts, Agritrop) ont été utilisées pour la documentation en utilisant l'expression suivante : ("West Africa" OR "Sub-Saharan Africa" OR "Afrique de l'Ouest") AND ("botanical pesticide" OR "pesticidal plants" OR "insecticidal plant" OR "essential oil") AND (pest* OR arthropod*OR insect* OR disease* OR "natural enemy" OR parasit*). Au total, 67 articles publiés entre 2004 et 2017 ont été sélectionnés en tenant compte de leur importance pour les cultures maraichères.

\section{DIVERSITÉ DES CULTURES MARAICHÈRES ET BIOAGRESSEURS ASSOCIÉS}

En Afrique de l'Ouest, les 27 espèces recensées comme cultures maraichères concernent des légumes traditionnels ou d'origine exotique les plus importants (Tableau 1). Cette diversité est fortement liée à la pluralité des communautés culturelles (locales et étrangères) et à la demande du marché et des organes consommés (Kanda et al., 2014).

À la diversité des légumes cultivés correspond celle des bioagresseurs observés (Tableau 2). Parmi eux, les arthropodes (insectes et acariens) causent des dégâts d'importance économique sur une large gamme de cultures (James et al., 2010 ; Sæthre et al., 2011a). Les chenilles des ravageurs comme Plutella xylostella Linné (Lepidoptera : Plutellidae), Hellula undalis Fabricius (Lepidoptera : Crambidea), Tuta absoluta Meyrick (Lepidoptera : Gelechiidae) sont capables d'engendrer d'énormes pertes de rendement (38 à $100 \%$ ) sur leurs cultures hôtes respectives (Asare-Bediako et al., 2010 ; James et al., 2010 ; Abbes et al., 2012).

D'autres groupes de bioagresseurs comme les nématodes à galles, les champignons et les bactéries peuvent causer également des pertes d'importance économique sur de nombreuses spéculations maraichères (James et al., 2010 ; Afouda et al., 2012). 


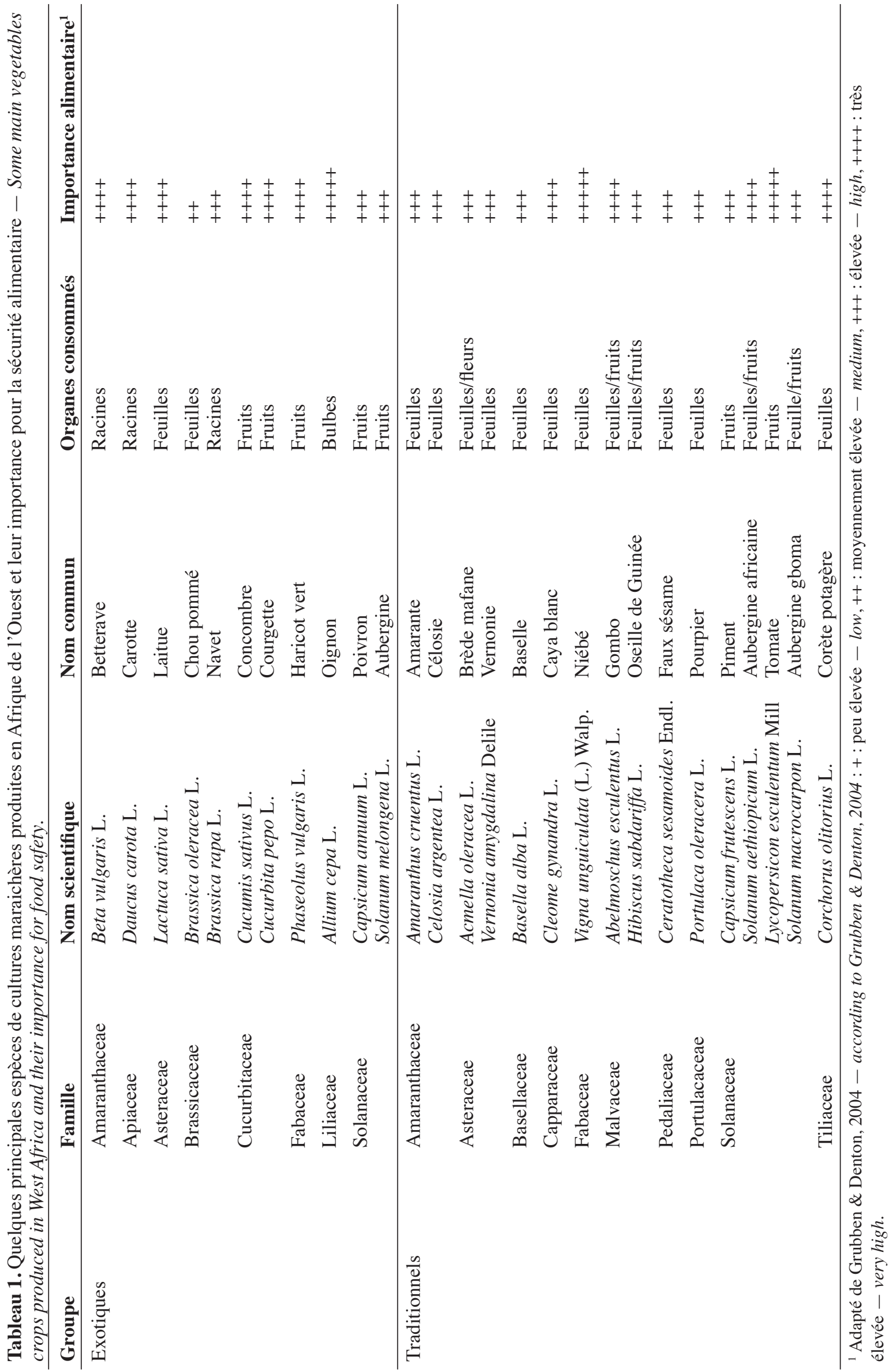




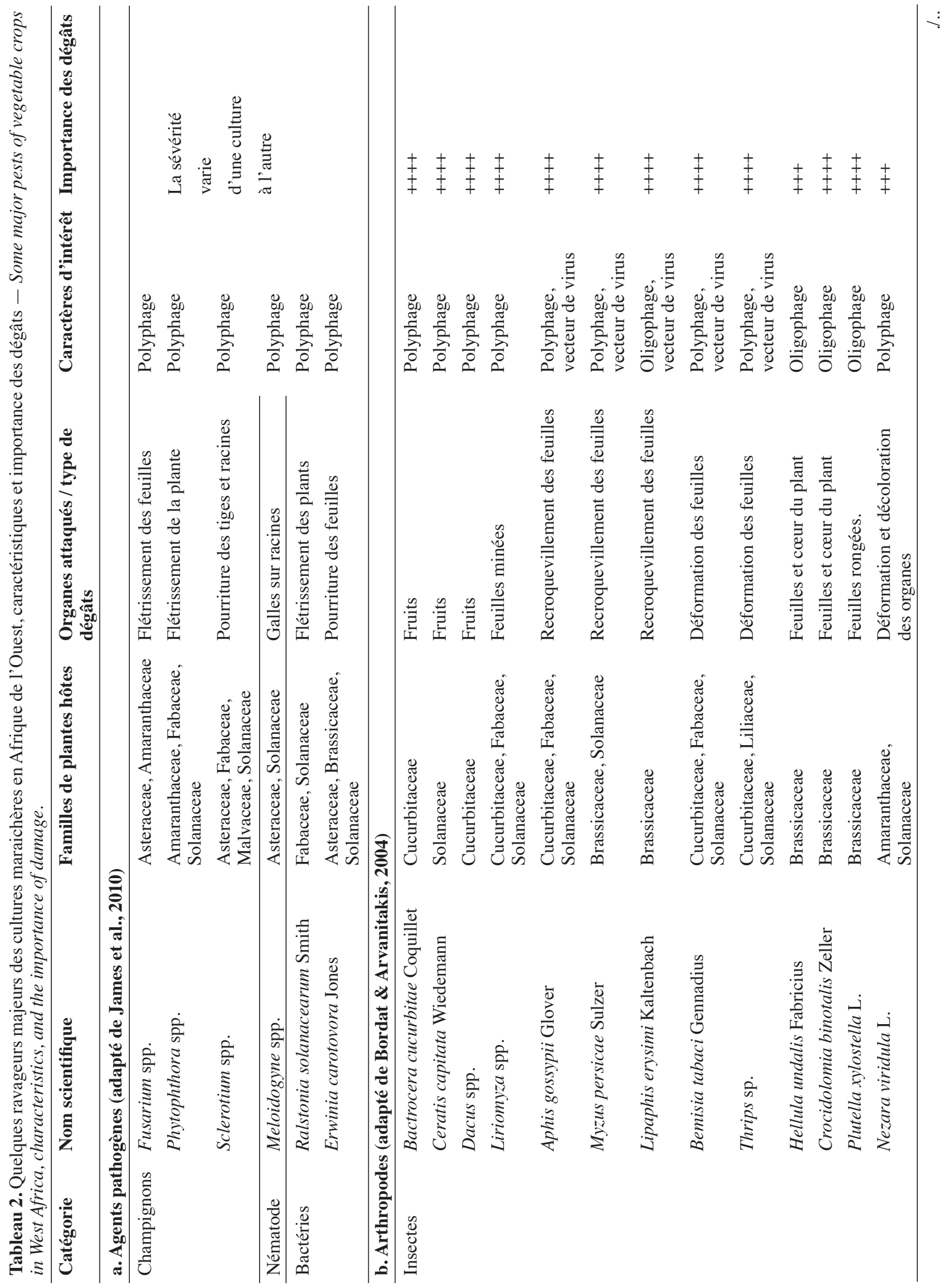




\section{PROBLÉMATIQUE DES PESTICIDES DE SYNTHĖSE COMME MOYENS DE LUTTE CONTRE LES BIOAGRESSEURS}

En Afrique, les maraichers utilisent principalement des produits de synthèse pour limiter les dégâts des ravageurs et améliorer la production (Kanda et al., 2013 ; Mondédji et al., 2015). Ces produits ont l'avantage d'agir sur un large spectre de bioagresseurs, permettant ainsi de maintenir une productivité suffisante (Mondédji et al., 2015). La plupart du temps, ils contiennent des substances actives (DDT : dichlorodiphényltrichloroéthane, endrine, lindane, profénofos, triazophos) prohibées par le règlement (CE) 1107/2009 (Commission européenne, 2009) ou non homologuées sur les cultures maraichères en Afrique de l'Ouest (CSP, 2016). Bien que les programmes " champs écoles » initiés en Afrique de l'Ouest aient permis de réduire leur usage (Settle \& Garba, 2011 ; Settle et al., 2014), les problèmes liés à leur utilisation demeurent toujours.

\subsection{Résistance des bioagresseurs et impact sur les auxiliaires}

La résistance des bioagresseurs est l'une des principales limites des pesticides de synthèse. Ce phénomène est mis en évidence sur différentes populations de bioagresseurs pour de nombreuses substances actives à travers le monde. En Afrique de l'Ouest, la résistance aux pyréthrinoïdes, organochlorés, organophosphorés et carbamates a été notifiée par exemple sur Bemicia tabaci Gennadius (Homoptera : Aleyrodidae) et P. xylostella (Houndété et al., 2010 ; Agboyi et al., 2016).

Les pesticides de synthèse sont généralement néfastes aux ennemis naturels (prédateurs et parasitoïdes) des ravageurs. Leur application sur les cultures entraine donc une réduction des populations de ces organismes qui sont bénéfiques pour la culture. Cette observation a été faite par exemple sur les populations de coccinelles, de syrphes et d'araignées prédatrices après traitement des parcelles de chou avec un insecticide à base d'émamectine benzoate (Amoabeng et al., 2013).

\subsection{Impacts des pesticides de synthèse sur l'homme et l'environnement}

L'efficacité immédiate des pesticides de synthèse fait oublier aux producteurs les risques sanitaires associés à leur utilisation (Ahouangninou et al., 2013). L'irritation cutanée, les maux de tête, la toux, le vertige, les troubles respiratoires, la fatigue, la diarrhée, etc. sont autant de symptômes d'intoxication dus à l'usage de ces pesticides (Kanda et al., 2009 ; Ahouangninou 
et al., 2011 ; Son et al., 2017). Des résidus de substances actives sont détectés dans divers produits maraichers, parfois à des quantités dépassant les limites maximales de résidus (LMR) fixées par le Codex Alimentarius ou l'Union européenne (Assogba-Komlan et al., 2007 ; Sæthre et al., 2011b ; Odhiambo et al., 2014).

La pollution environnementale, quant à elle, résulte aussi bien des effets de surdosage que de la mauvaise gestion des emballages (Kanda et al., 2013 ; Son et al., 2017). Au Bénin, l'endosulfan, le DDT et l'endrine ont été détectés dans différentes espèces de poissons (Yehouenou A. Pazou et al., 2006) et échantillons de sol (Assogba-Komlan et al., 2007). Ngom et al. (2012) ont mis en évidence la présence des résidus de métamidophos, de l'endosulfan et du diméthoate dans les eaux de puits en zone agricole au Sénégal.

L'utilisation quotidienne de ces produits (légumes, eaux, produits aquatiques) contaminés avec des pesticides constitue sans doute l'un des principaux facteurs de risque d'intoxication pour les consommateurs.

\section{PLANTES PESTICIDES COMME ALTERNATIVES AUX PESTICIDES DE SYNTHÈSE}

L'usage des plantes pesticides se révèle être une pratique ancestrale en Afrique. En effet, de nombreuses plantes sont connues et utilisées pour leurs activités biocides (toxique, répulsive, anti-appétant) vis-à-vis d'une large gamme de bioagresseurs (Tableaux 3 et 4). Elles peuvent être utilisées sous forme d'extraits de plantes en protection foliaire (Mochiah et al., 2011 ; Mondédji et al., 2014a) ou en association avec d'autres cultures (Asare-Bediako et al., 2010 ; Baidoo et al., 2012). Des huiles essentielles (liquide concentré de composés organiques volatiles de plantes) ou des plantes entières sont également utilisées dans les greniers de denrées stockées (Anjarwalla et al., 2016).

\subsection{Potentialités des extraits de plantes sur les bioagresseurs et impact sur les auxiliaires}

Divers organes des plantes pesticides sont utilisés pour la préparation des extraits (Tableaux 3 et $\mathbf{4}$ ). Ces derniers peuvent être des extraits aqueux ou organiques, des huiles ou des huiles essentielles obtenues le plus souvent par hydrodistillation.

\section{Effets des extraits aqueux et organiques sur les bioagresseurs}

Effets sur les champignons et nématodes phytopathogènes. L'action biocide d'extraits de plantes sur champignons se manifeste par l'inhibition de la sporulation ou par une réduction de la sévérité de la maladie. Okereke et al. (2007) ont montré que l'application des extraits aqueux d'Azadirachta indica A.Juss. (Meliaceae), de Carica papaya L. (Caricaceae) et d'Hyptis suaveolens (L.) Poit. (Lamiaceae) sur des plants de tomate infectés par Sclerotium rolfsii Saccardo permet de réduire la sévérité de la maladie et d'obtenir une meilleure croissance des plants. Une expérience similaire de Zirihi et al. (2008) a pu montrer que pour des concentrations supérieures à $6 \mathrm{~g} \cdot \mathrm{l}^{-1}$, l'extrait aqueux de Combretum racemosum P.Beauv. (Combretaceae) inhibe totalement la croissance mycélienne de Pythium aphanidermatum Edson, Fusarium oxysporum f. sp. radicilycopersici Forl. et Macrophomina phaseoli Maubl. Selon Obi \& BarriusoVargas (2013), l'extrait aqueux de Xylopia aethiopica (Dunal) A.Rich. (Annonaceae) serait en mesure d'inhiber la germination des spores et la croissance des colonies de Colletotrichum destructivum O'Gara. Par contre, aucun effet fongicide n'a pu être observé avec ce même extrait aqueux sur $S$. rolfsii, contrairement à l'huile essentielle qui s'est montrée très efficace sur le même champignon (Bolou Bi Bolou et al., 2015).

$\mathrm{Au}$ niveau des nématodes, on peut observer une inhibition de l'éclosion ou de l'émergence des larves après usage d'extraits de diverses plantes telles que A. indica, Chromolaena odorata (L.) R.M.King \& H.Rob. (Asteraceae), Nicotiana tabacum L. (Solanaceae), C. papaya, Cannabis sativa $\mathrm{L}$. (Cannabaceae), Cassia alata L. (Caesalpiniaceae), Vernonia amygdalina Delile (Asteraceae) sur les nématodes du genre Meloidogyne (Adegbite, 2011). Afouda et al. (2012) ont fait les mêmes observations sur ces Meloidogyne tout en mettant l'accent sur la variabilité de l'action nématicide selon la plante et l'organe utilisé. Récemment, il a été démontré que l'amendement des plants de piment infestés par une poudre de feuilles d'A. indica induit une baisse importante des populations de nématodes avec pour conséquence une meilleure croissance des plants traités, contrairement aux plants non traités (Kankam \& Sowley, 2016).

Effets sur les arthropodes ravageurs. En expériences de laboratoire, les observations se focalisent essentiellement sur les paramètres biologiques (mortalité, appétence, oviposition, éclosion des œufs, émergence des adultes, etc.) ou le comportement des individus. Ainsi, l'effet répulsif d'A. indica, de Piper guineense Schumach \& Thonn. (Piperaceae), de $X$. aethiopica, de Garcinia kola Heckel (Culsiaceae) et d'Aframomum melegueta K.Schum. (Zingiberaceae) sur la chrysomèle défoliatrice du gombo (Podagrica uniforma Jacoby) a été mise en évidence par Echereobia et al. (2010). En effet, ces auteurs ont montré que des extraits aqueux à $10 \%$ de ces plantes induisaient une activité répulsive variant de 20 à $100 \%$ 


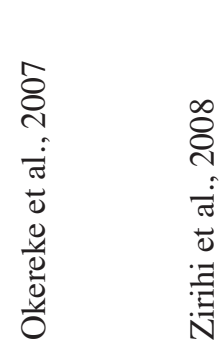

กับ

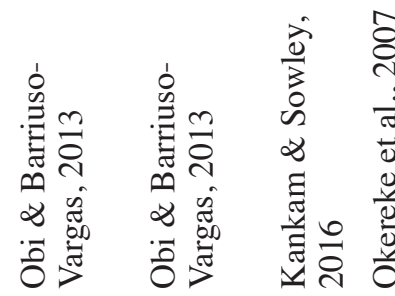

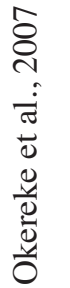

:

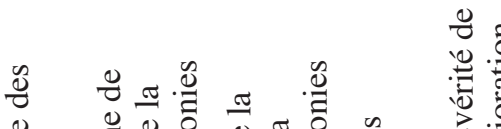

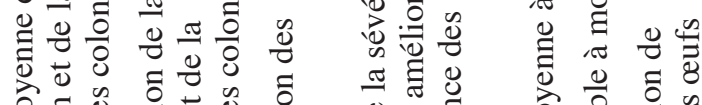

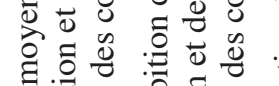

卷

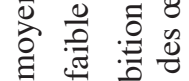

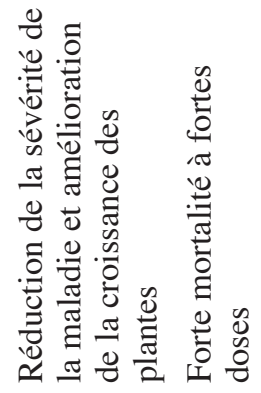

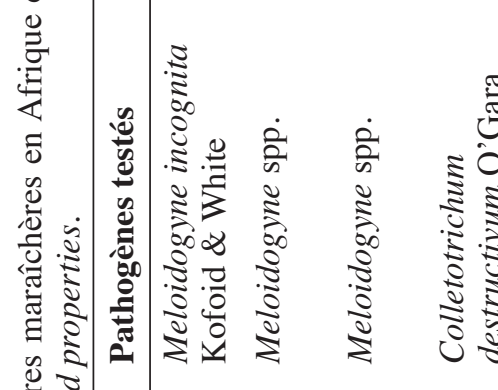

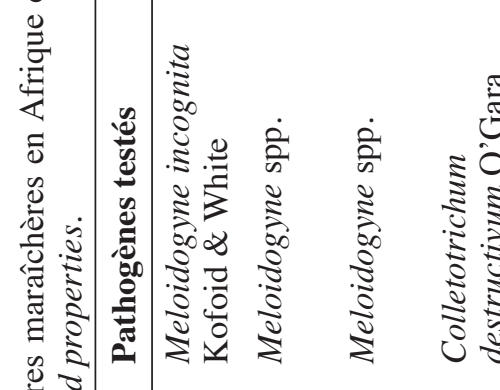

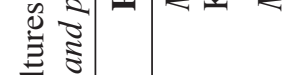

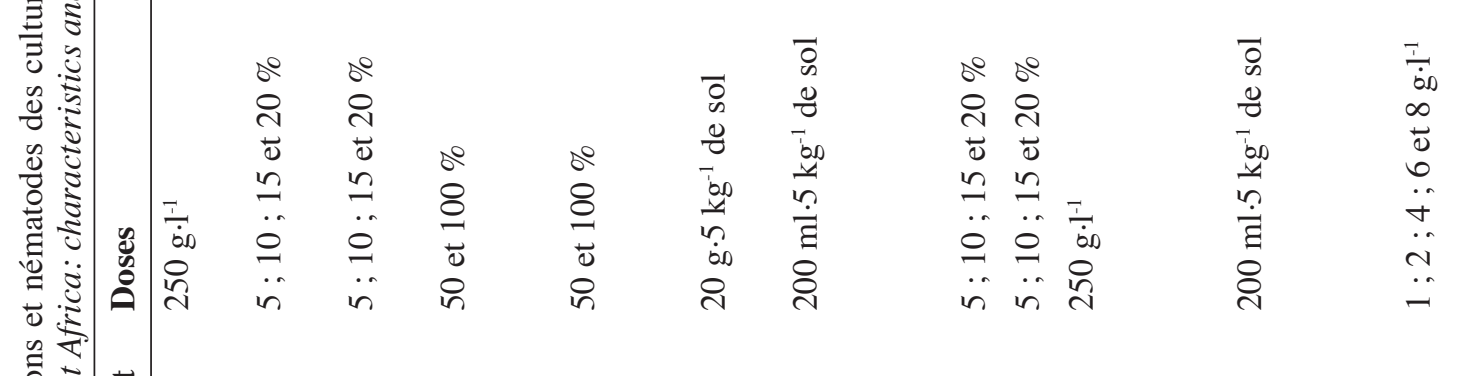

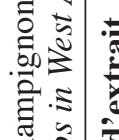

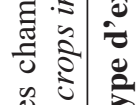

吾

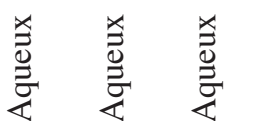

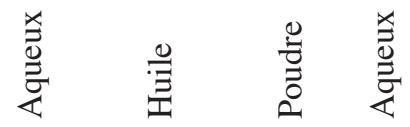

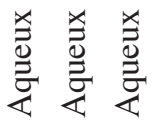

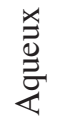

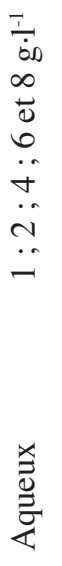

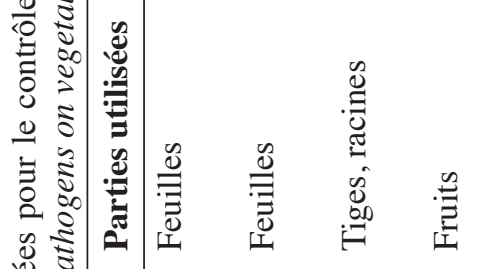

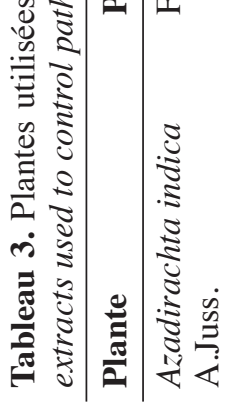

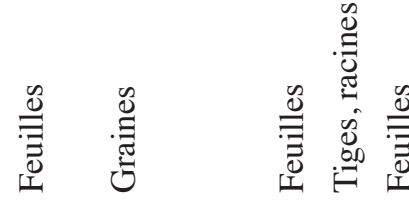
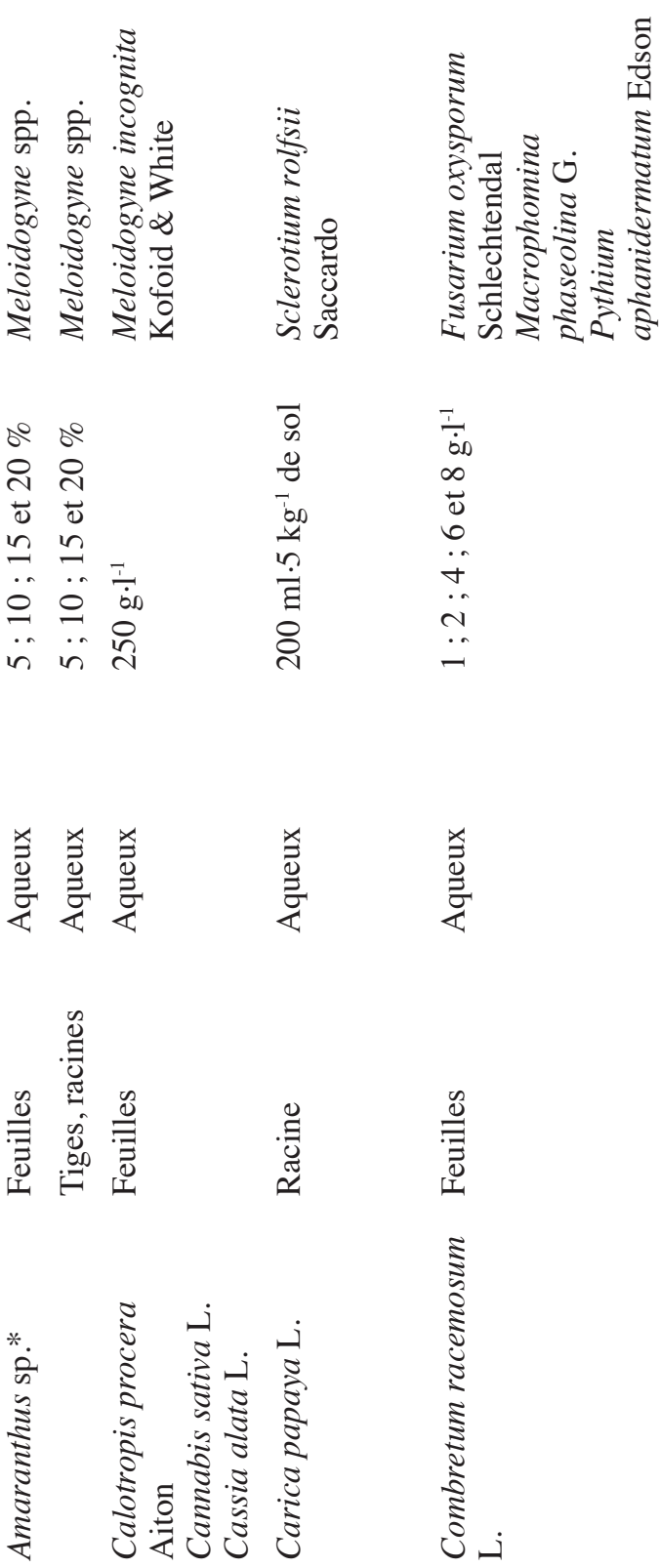


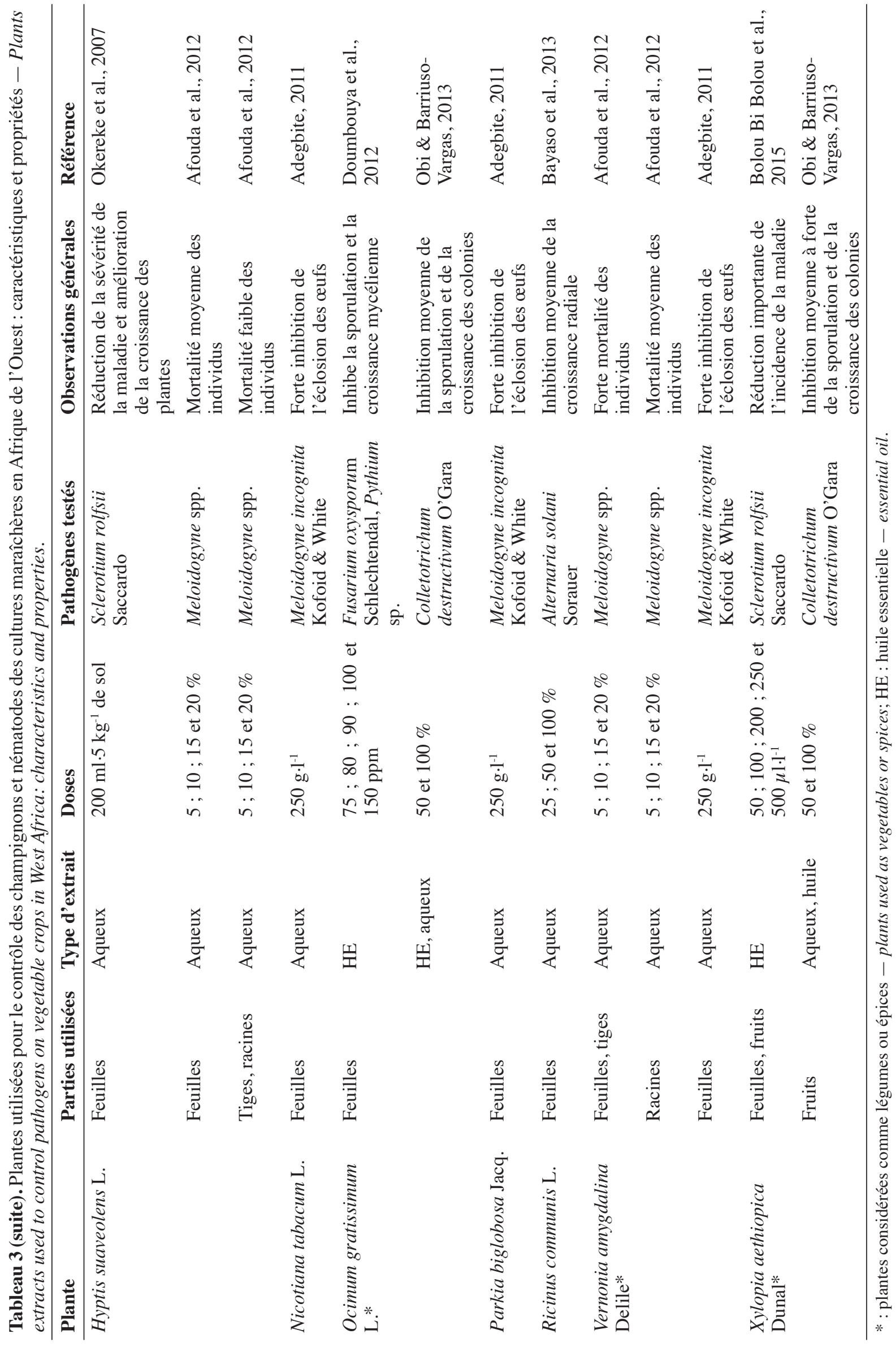




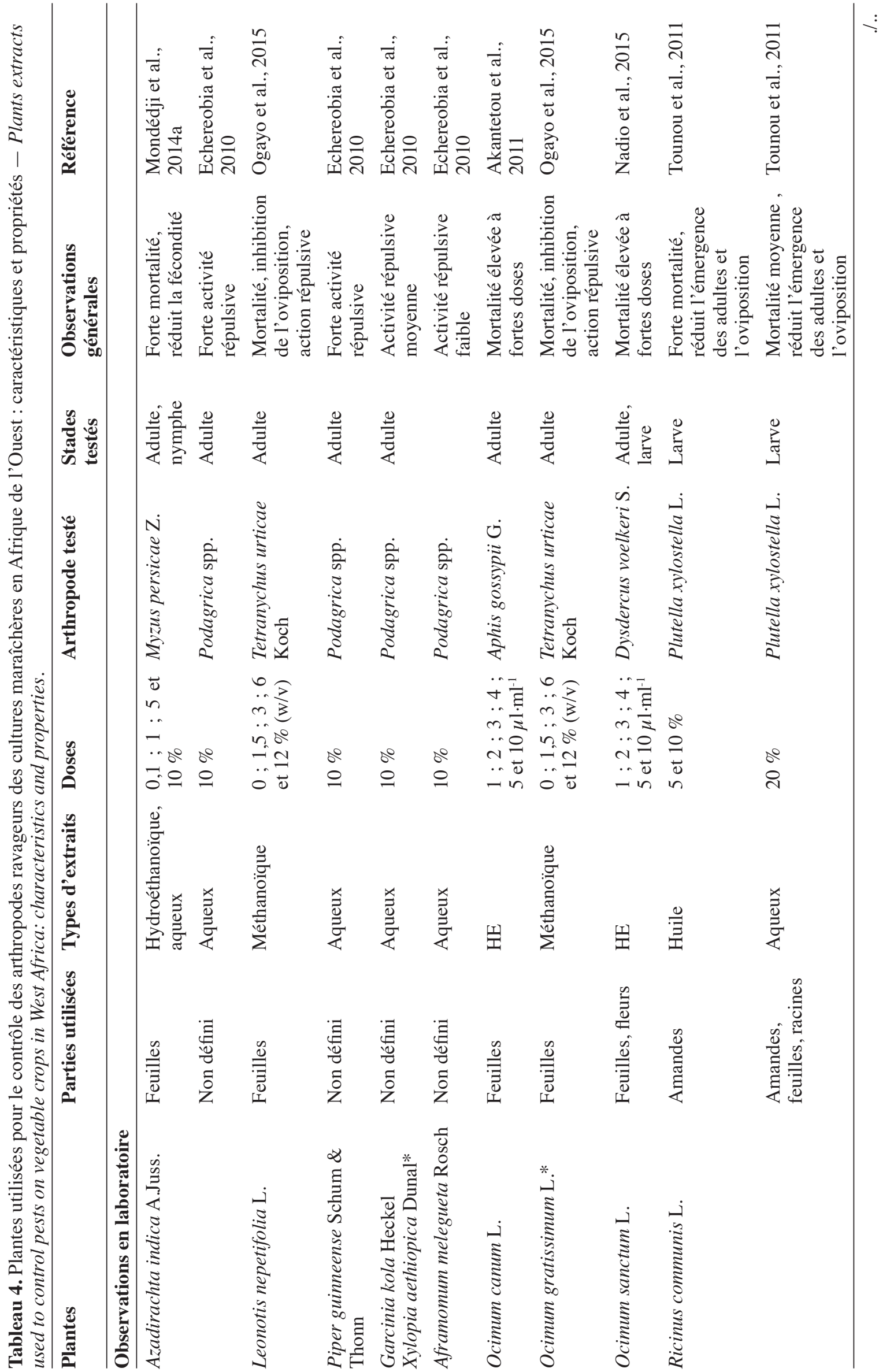


Lutte contre les ravageurs des cultures maraichères

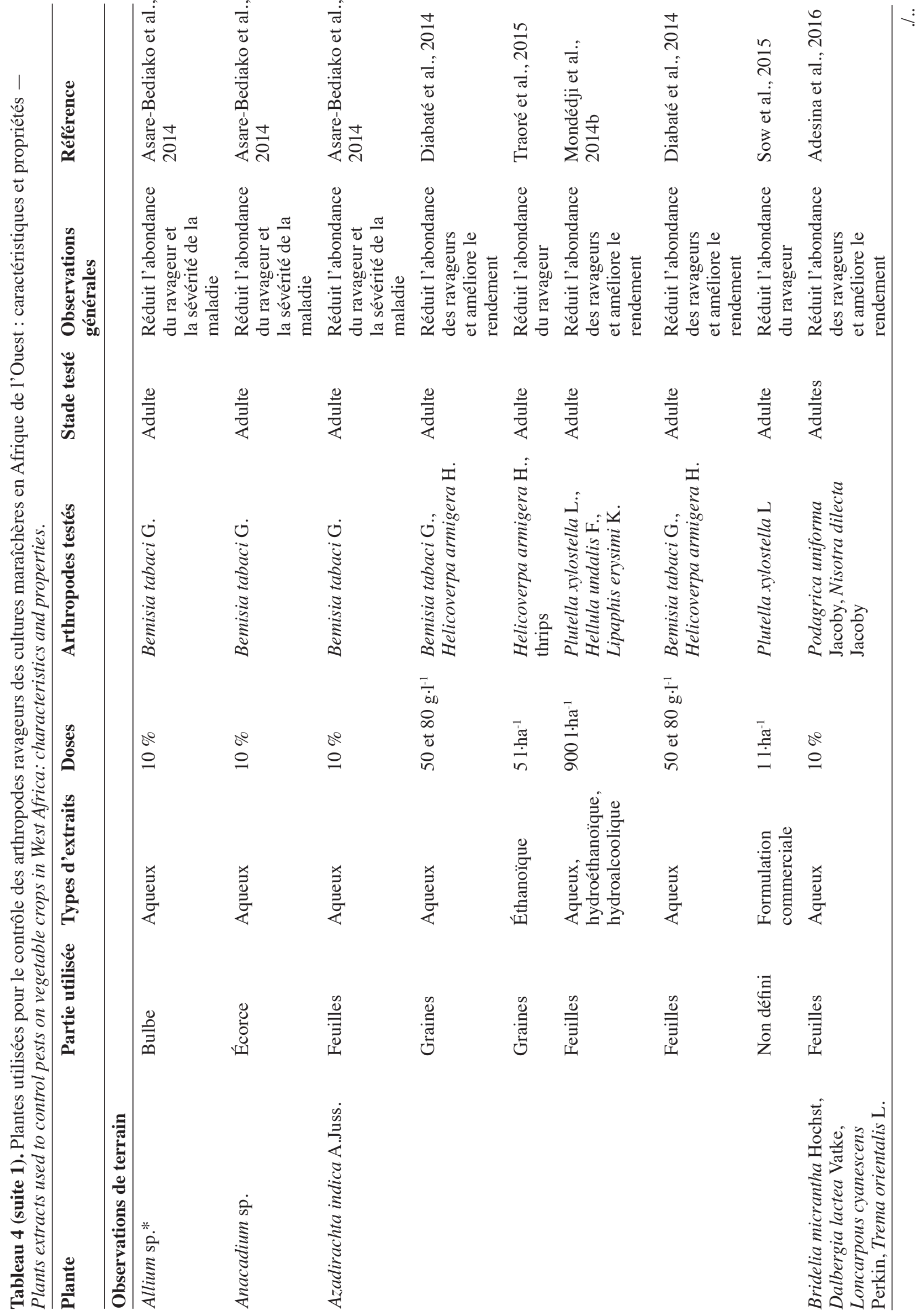


selon la plante. Tounou et al. (2011) ont démontré que des extraits aqueux de Ricinus communis L. (Euphorbiaceae) sur des larves de $P$. xylostella causent la mortalité (54 à $71 \%$ ), la déformation (ailes et pattes) des adultes à l'émergence et réduit l'oviposition. Des travaux similaires ont révélé qu'un extrait de feuilles d'A. indica a une forte activité insecticide (mortalité $>95 \%$ ) et réduit considérablement la fécondité de $M$. persicae (Mondédji et al., 2014a). Selon les mêmes auteurs, l'application de cet extrait (A. indica) sur des plants modifierait considérablement le comportement alimentaire de ce puceron (sondage par les stylets, pénétration du phloème, salivation et ingestion). Sur Tetranychus urticae Koch, il a été également notifié que les extraits de Leonotis nepetifolia (L.) R.Br. et d'Ocimum gratissimum L. (Lamiaceae) peuvent non seulement inhiber l'oviposition de cet acarien, mais aussi provoquer une forte mortalité (90\%) (Ogayo et al., 2015).

Dans les conditions d'expérimentations en champ, l'efficacité des extraits de plantes est généralement mesurée à travers l'abondance des populations des ravageurs ou la sévérité des dégâts. En traitant les parcelles de cultures (chou et gombo) avec l'extrait de graines d'A. indica, Gnago et al. (2010) ont remarqué que les populations de chenilles et de pucerons étaient moins importantes sur les parcelles traitées que sur celles non traitées. Des résultats similaires ont été obtenus avec les extraits aqueux de substances épicées (Sinapis nigra L. [Brassicaceae], X. aethiopica, $N$. tabacum) sur les insectes ravageurs de Phaseolus vulgaris L. (Fabaceae) (Kambou \& Guissou, 2011). En effet, ces auteurs ont montré qu' avec $400 \mathrm{l} \cdot$ ha $^{-1}$ d'extrait, ces substances épicées peuvent réduire de 61 à $78 \%$ la population des aleurodes, des thrips, des coléoptères, en comparaison aux parcelles témoins non traitées. Cela permet d'assurer un rendement équivalent à celui obtenu sur les parcelles traitées avec un insecticide de synthèse comme la deltaméthrine (Kambou \& Guissou, 2011). Une baisse considérable des ravageurs du gombo et de l'aubergine (A. gossypii, Podagrica 
spp., B. tabaci, Earias sp., Dysdercus superstitiosus H. Schaffer, Z. variegatus L., Urentius hysterricellus Richter et Leucinodes orbonalis Guénée) a été mentionnée après traitement avec des extraits d'Allium sp. (Liliaceae) $\left(30 \mathrm{~g} \cdot \mathrm{l}^{-1}\right)$ et de C. papaya $\left(92 \mathrm{~g} \cdot \mathrm{l}^{-1}\right)$ par Mochiah et al. (2011). Asare-Bediako et al. (2014) ont conforté les observations faites par Kambou \& Guissou (2011) en soulignant la capacité des extraits d'A. indica, de C. papaya, d'Allium sp., de Capsicum sp. (Solanaceae), d'Anacardium sp. (Anacardiaceae) à minimiser la sévérité de la virose due aux aleurodes et d'augmenter le rendement des parcelles traitées. De tels résultats ont été également notés après usage des extraits aqueux de Fabaceae (Loncarpous cyanescens Perkin, Dalbergia lactea Vatke) pour le contrôle des chrysomèles en culture de gombo (Adesina et al., 2016).

D'autres travaux comparant les extraits de plantes aux insecticides classiques ont pu démontrer que certains extraits peuvent présenter la même efficacité que les insecticides de synthèse. Ainsi, les extraits de N. tabacum, Cassia sophera L. (Fabaceae), Jatropha curcas L., R. communis, Ageratum conyzoides (L.) L. (Asteraceae), C. odorata et Synedrella nodiflora (L.) Gaertn. (Asteraceae) seraient aussi efficaces que l'émamectine benzoate et la lambda-cyhalothrine pour le contrôle de $P$. xylostella et de $B$. brassicae sur culture de chou (Amoabeng et al., 2013). Le même constat a été fait avec les extraits d'Allium sativum L. (Liliaceae), de $C$. frutescens et d'A. indica comparés à l'émamectine et un pesticide binaire (cyperméthrine + diméthoate) sur les ravageurs du chou et du haricot vert (Fening et al., 2014 ; Mondédji et al., 2014b). Des observations similaires ont été également mentionnées avec l'extrait $J$. curcas comparé aux pyréthrinoïdes (deltaméthrine, cyperméthrine) pour le contrôle des ravageurs de la tomate (Diabaté et al., 2014) et entre un produit à base d'A. indica et le diméthoate pour lutter contre P. xylostella sur chou (Sow et al., 2015).

\section{Effets des huiles et des huiles essentielles sur les bioagresseurs}

Effets sur les agents phytopathogènes. En comparant l'effet fongicide d'huiles essentielles de plantes à celui des fongicides classiques, il a été constaté que l'huile d'O. gratissimum inhibe la germination des spores et la croissance mycélienne de Fusarium oxysporum f. sp. radicis lycopersici et Pythium sp. avec un effet relativement équivalent à celui des fongicides de synthèse (Doumbouya et al., 2012). Dans cette même logique, il a été démontré que l'huile essentielle des fruits de $X$. aethiopica inhibe fortement la croissance mycélienne de $S$. rolfsii, avec pour conséquence une réduction considérable de l'incidence de la maladie sur les plants de tomate traités comparés aux plants non traités (Bolou Bi Bolou et al., 2015).
Effets sur les arthropodes ravageurs. Une expérience de laboratoire sur $P$. xylostella mentionne qu'à faible dose (5\%), l'huile de R. communis induit une déformation et retarde l'émergence des adultes issus des larves traitées (Tounou et al., 2011). En revanche, avec des doses élevées (10\%), ces auteurs obtiennent une forte mortalité des larves. Par ailleurs, il s'est révélé que l'huile essentielle d'Ocimum canum Sims (Lamiaceae) à $4 \mu \mathrm{l} \cdot \mathrm{ml}^{-1}$ est très toxique (100\% de mortalité) pour A. gossypii (Akantetou et al., 2011). Cette toxicité est probablement liée au composé majoritaire de cette huile (terpinéol-4), dont l'efficacité est similaire à celle de l'huile complète. Sur P. xylostella, Laba et al. (2012) ont montré qu'au bout de $48 \mathrm{~h}$, l'effet de l'huile essentielle $\left(2 \mathrm{~g} \cdot \mathrm{l}^{-1}\right)$ de Cymbopogon schoenanthus (L.) Spreng. (Poaceae) est six fois supérieur $(60 \%$ de mortalité) à celui du diméthoate $(10 \%$ de mortalité) à une concentration de $0,25 \mathrm{mg}$ de substance active pour $40 \mu \mathrm{l}$ de solution. L'activité biocide de cette huile essentielle ( $C$. schoenanthus) a été notifiée également sur A. gossypii (Bokobana et al., 2014). Nadio et al. (2015) ont, pour leur part, mis en évidence l'activité insecticide de l'huile essentielle d'Ocimum sanctum L. (Lamiaceae) sur les larves de Dysdercus voelkeri Schmidt. En investiguant sur l'effet de mélange de l'huile essentielle de C. schoenanthus et de l'huile d'A. indica sur P. xylostella, Kolani et al. (2016) ont démontré que le mélange de ces huiles a une efficacité plus élevée que si elles sont utilisées séparément. En condition naturelle (plein champ), Habou et al. (2011) ont confirmé l'activité biocide de l'huile de Jatropha sp. sur les ravageurs du niébé. En effet, l'application de cette huile au $35^{\mathrm{e}}, 45^{\mathrm{e}}$ et $60^{\mathrm{e}}$ jours après semis a permis de réduire l'abondance des thrips (Megalurothrips sjöstedt Trybom), des punaises (Anoplocnemis curvipes Fabricus) et la sévérité des attaques d'Aphis craccivora Koch, ainsi que d'augmenter le rendement par rapport au témoin non traité.

Impacts des extraits de plantes sur les organismes auxiliaires. En considérant le faible nombre d'études qui leur a été consacré, on peut penser que les extraits de plantes ont peu d'impacts négatifs sur les auxiliaires en comparaison de ceux occasionnés par les insecticides de synthèse. En effet, leur application permet de maintenir un équilibre écologique entre ravageurs et auxiliaires (Mochiah et al., 2011). Comparé aux insecticides de synthèse, Amoabeng et al. (2013) ont, par exemple, constaté que la population des auxiliaires (Coccinella magnifica Redtenbacher, Episyrphus balteatus De Geer) et des araignées prédatrices était plus importante sur les parcelles de chou traitées avec des extraits de plants que des insecticides de synthèse. Similairement, des taux de parasitisme élevés de $P$. xylostella, notamment par les hyménoptères Oomyzus sokolowskii Kurdjumov et Apanteles litae 
Nixon, ont été enregistrés dans les parcelles de chou traitées avec un produit à base d'A. indica comparé à celles traitées au diméthoate (Sow et al., 2015). Cet équilibre écologique est beaucoup plus en faveur de la lutte biologique que le déséquilibre écologique causé par l'usage des pesticides de synthèse.

\subsection{Plantes pesticides et association des cultures}

L'association de cultures d'espèces différentes consiste à produire différentes spéculations sur une même parcelle. Elle est généralement bénéfique pour les producteurs lorsqu'elle est bien organisée car elle favorise les interactions au sein de la communauté des arthropodes. Les avantages de cette forme de production sur le contrôle des bioagresseurs ont fait l'objet d'une synthèse bibliographique (Malézieux et al., 2009).

Interaction avec les arthropodes ravageurs. L'association des cultures permet de réduire l'abondance des ravageurs de la culture principale, comme par exemple celle du chou. Associé à la tomate, l'oignon ou le piment, une réduction de l'abondance des ravageurs du chou ( $P$. xylostella, B. tabaci, $B$. brassicae, Z . variegatus et $H$. undalis) est constatée dans les parcelles associées (Asare-Bediako et al., 2010 ; Mochiah et al., 2011 ; Baidoo et al., 2012). Le même constat a été mentionné sur des parcelles associées A. esculentus - O. basilicum pour le contrôle des ravageurs d'A. esculentus (Amoatey \& Acquah, 2010). De même, Assogba-Komlan et al. (2012) ont montré que les parcelles de chou en association avec des plants d' $O$. gratissimum étaient moins infestées par les chenilles des lépidoptères $S$. littoralis, $P$. xylostella et $H$. undalis que celles de chou cultivé seul. Cette réduction de l'incidence des dégâts entraine une augmentation des rendements (Amoatey \& Acquah, 2010 ; Mochiah et al., 2011 ; Assogba Komlan et al., 2012).

Interaction avec les arthropodes auxiliaires. Dans les rares études réalisées sous les tropiques, en Afrique la réduction des populations des insectes ravageurs dans les systèmes d'association culturale est souvent attribuée à la présence des auxiliaires. Généralement, la population de ces organismes ne diffère pas significativement entre les parcelles associées et non associées (Mochiah et al., 2011). En effet, les parcelles non associées sont plus infestées et constituent une ressource alimentaire importante pour les auxiliaires, ce qui expliquerait notamment le nombre important d'auxiliaires sur ces parcelles. Néanmoins, la présence de ces auxiliaires permet de maintenir la pression des ravageurs dans les parcelles associées et de minimiser les dégâts des ravageurs (Mochiah et al., 2011) et l'utilisation des pesticides de synthèse (Amoatey \& Acquah, 2010).

\section{DISCUSSION}

Pour remédier aux problèmes résultants de l'utilisation des pesticides de synthèse, les plantes pesticides se présentent comme une alternative prometteuse dans le contexte de l'Afrique de l'Ouest. En effet, la littérature scientifique démontre que de nombreuses plantes de la flore ouest africaine disposent d'un énorme potentiel biocide sur une large gamme de bioagresseurs. La plupart de ces plantes ne sont pas cultivées, telle que $A$. indica, espèce sans doute la plus utilisée comme plante pesticide. Mais comme toute autre méthode de lutte, l'utilisation de plantes pesticides présente des avantages et des limites.

\subsection{Avantages de l'usage des plantes pesticides}

D'une façon générale, les extraits de plantes pesticides sont moins dangereux que les pesticides de synthèse (Wainwright et al., 2013), même si certains extraits de plantes comme la nicotine peuvent être toxiques à certaines doses sur les organismes vivants (Slotkin et al., 2016). La décomposition assez rapide et la faible action polluante sont des avantages des extraits de plantes (Wainwright et al., 2013). Dans certaines conditions, les extraits de plantes peuvent avoir une efficacité comparable à celle des insecticides classiques. Si cette dernière efficacité n'est pas complète, elle peut néanmoins permettre de maintenir la population des ravageurs en dessous du seuil de nuisibilité et réduire l'usage des pesticides de synthèse utilisés sur les légumes. En termes de résidus de pesticides, la qualité sanitaire des cultures est ainsi améliorée, ce qui peut minimiser les risques d'intoxication des populations. Les produits naturels issus des plantes peuvent aussi permettre d'accroître les rendements avec un rapport cout/bénéfice comparable à celui des pesticides de synthèse (Amoabeng et al., 2014). Dans le cadre des cultures associées, les plantes pesticides assurent un équilibre écologique entre ravageurs et auxiliaires. Ainsi, l'ensemble de ces éléments montre que les extraits de plantes pesticides peuvent dans certaines situations substituer valablement les pesticides de synthèse en matière d'efficacité. Ils devraient ainsi constituer une des composantes essentielles des programmes de gestion intégrée des bioagresseurs.

\subsection{Limites à l'usage des plantes pesticides}

Les contraintes liées à l'utilisation des plantes pesticides dans la protection des cultures sont de deux ordres : les limites liées à la perception générale de leur usage par 
les producteurs eux-mêmes et celles résultant du cadre institutionnel et règlementaire.

Limites liées à la perception des producteurs. Malgré les avantages énumérés, les plantes pesticides sont très peu utilisées par les producteurs maraichers. En effet, le temps nécessaire pour réaliser les extraits est souvent considéré comme trop long, le nombre de traitements requis trop important et la spécificité de ces extraits forment quelques-unes des raisons qui n'encouragent pas leur utilisation par les producteurs (Adékambi et al., 2010). En matière d'efficacité, la lenteur de leurs effets, leur faible rémanence et le spectre d'action très réduit, comparé à celui des produits de synthèse, sont souvent considérés comme un inconvénient par les producteurs (Adékambi et al., 2010 ; Tounou et al., 2011). Ces produits sont généralement proposés par des petites unités de production ou des associations locales qui les fabriquent en très faibles quantités, ce qui limite leur disponibilité. En effet, ces petites unités de transformation ne disposent souvent pas d'assez de ressources matérielles et financières pour pouvoir rentabiliser leur activité. Lorsqu'ils sont vendus dans le commerce, ces extraits ou formulations coutent relativement plus chers que les pesticides de synthèse (James et al., 2010 ; Adétonah et al., 2011).

\section{Limites liées à la règlementation et à l'homologation.}

En Afrique, la législation sur l'homologation, la règlementation et la commercialisation des biopesticides d'origine végétale (toutes formulations à base de substances actives d'origine végétale, destinées à la protection des produits végétaux) reste encore très embryonnaire. En 2017, seul le Ghana dispose d'une règlementation en Afrique de l'Ouest, en plus de celle du Kenya en Afrique de l'Est (Fotio \& Temwa, 2012). L'homologation des biopesticides dans les pays africains reste un défi, car leur utilisation doit faire l'objet d'une évaluation identique à celle des pesticides de synthèse. Cette démarche est inaccessible pour une petite unité de fabrication locale. Les questions de la variabilité de l'efficacité des extraits de plantes (Tableaux 3 et 4) et celle du prix au producteur, qui doit rester abordable, sont également deux aspects à travailler.

\section{CONCLUSIONS ET PERSPECTIVES}

Les pesticides végétaux sont loin de remplacer rapidement les pesticides de synthèse, notamment en grandes cultures. En production maraichère néanmoins, ils peuvent être une solution alternative et contribuer à la préservation de la santé des populations. Parmi les plantes considérées comme intéressantes, les espèces d'Ocimum, présentes dans la plupart des pays africains, ont des vertus thérapeutiques et médicinales. Certaines sont consommées comme des légumes feuilles ou des épices en Afrique de l'Ouest. Explorer leurs capacités à contrôler les bioagresseurs des cultures maraichères et optimiser leur utilisation pourraient ainsi être une bonne perspective de recherche. Mais d'une manière plus générale, pour faciliter l'adoption des plantes pesticides, la population doit être davantage sensibilisée sur la sécurité renforcée des produits traités avec les pesticides à base de plante et leurs avantages à long terme. Cela nécessite une volonté politique d'États prêts à soutenir, subventionner et encourager les partenariats privé-public pour le développement de cette filière particulière. En se référant aux plantes pesticides recensées dans cette revue, on constate que la plupart d'entre elles sont des plantes non cultivées. Pour le producteur, qui ne perçoit pas l'avantage direct et immédiat dont il peut bénéficier en cultivant ce genre de plante, il faudra le convaincre du bénéfice qu'il pourra en espérer, par exemple en lui assurant qu'il pourra vendre sa production à une entité locale de transformation. Il trouvera plus de motivation à produire une plante du genre Ocimum considérée comme légume dont il pourra obtenir un avantage immédiat. Dans le contexte plus général de la perte de biodiversité liée aux changements climatiques, il apparait important de prendre des mesures qui permettront d'assurer la pérennité de ces espèces.

\section{Remerciements}

Ce travail entre dans le cadre du projet de thèse financé par le Projet Dream ACP du programme Erasmus Mundus. Un sincère remerciement à Momar Talla GUEYE $(\mathrm{PhD})$ et Hervé KOMBIENI $(\mathrm{PhD})$ pour la relecture du manuscrit et leurs recommandations.

\section{Bibliographie}

Abbes K., Harbi A. \& Chermiti B., 2012. The tomato leafminer Tuta absoluta (Meyrick) in Tunisia: current status and management strategies. Bull. OEPP/EPPO Bull., 42(2), 226-233.

Adegbite A.A., 2011. Effects of some indigenous plant extracts as inhibitors of egg hatch in root-knot nematode (Meloidogyne incognita race 2). Am.J. Exp. Agric., 1(3), 96-100.

Adékambi S.A., Adégbola P.Y. \& Arouna A., 2010. Perception paysanne et adoption des biopesticides et/ou extraits botaniques en production maraichère au Bénin. In : Contributed Paper Presented at the Joint $3^{\text {rd }}$ African Association of Agricultural Economists (AAAE) and $48^{\text {th }}$ Agricultural Economists Association of South Africa (AEASA) Conference, September 19-23, Cape Town, South Africa. 
Adesina J.M., Ileke K.D., Yallappa R. \& Ofuya T.I., 2016. Insecticidal evaluation of Bridelia micrantha and Dalbergia lactea aqueous extracts for the control of Podagrica uniforma (Jacoby) and Nisotra dilecta (Jacoby) (Coleoptera: Chysomelidae) infestation on okra. AGRIVITA J. Agric. Sci., 38(3), 269-274.

Adétonah A. et al., 2011. Perceptions et adoption des méthodes alternatives de lutte contre les insectes des cultures maraichères en zone urbaine et péri-urbaine au Bénin et au Ghana. Bull. Rech. Agron. Bénin, 69, 1-10.

Afouda L. et al., 2012. Effet de l'hyptis (Hyptis suaveolens), du neem (Azadirachta indica), du vernonia (Vernonia amygdalina) et de l'amarante (Amaranthus sp.) sur les nématodes à galles (Meloidogyne spp.) en cultures maraichères. Agron. Afr., 24(3), 209-218.

Agboyi L.K. et al., 2016. Pesticide resistance in Plutella xylostella (Lepidoptera: Plutellidae) populations from Togo and Benin. Int. J. Trop. Insect Sci., 36(4), 204-210.

Ahouangninou C., Fayomi E.B. \& Martin T., 2011. Évaluation des risques sanitaires et environnementaux des pratiques phytosanitaires des producteurs maraichers dans la commune rurale de Tori-Bossito (Sud-Bénin). Cah. Agric., 20(3), 216-222.

Ahouangninou C. et al., 2013. Using Aedes aegypti larvae to assess pesticide contamination of soil, groundwater and vegetables. Br. Biotechnol. J., 3(2), 143-157.

Akantetou P.K. et al., 2011. Évaluation du potentiel insecticide de l'huile essentielle de Ocimum canum Sims sur Aphis gossypii Glover (Homoptera : Aphididae) au Togo. Int. J. Biol. Chem. Sci., 5(4), 1491-1500.

Amoabeng B.W. et al., 2013. Tri-trophic insecticidal effects of African plants against cabbage pests. PLoS One, 8(10), e78651.

Amoabeng B.W., Gurr G.M., Gitau C.W. \& Stevenson P.C., 2014. Cost:benefit analysis of botanical insecticide use in cabbage: implications for smallholder farmers in developing countries. Crop Prot., 57, 71-76.

Amoatey C.A.\& Acquah E., 2010. Basil (Ocimum basilicum) intercrop as a pest mangement tool in okra cutivation in the Accra plains. Ghana J. Hortic., 8, 65-70.

Anjarwalla P. et al., 2016. Handbook on pesticidal plants. Nairobi: World Agrofor Cent (ICRAF).

Asare-Bediako E., Addo-Quaye A.A. \& Mohammed A., 2010. Control of diamondback moth (Plutella xylostella) on cabbage (Brassica oleracea var capitata) using intercropping with non-host crops. Am.J.Food Technol., 5(4), 269-274.

Asare-Bediako E., Addo-Quaye A. \& Bi-Kusi A., 2014. Comparative efficacy of plant extracts in managing whitefly (Bemisia tabaci Gen.) and leaf curl disease in okra (Abelmoschus esculentus L.). Am. J. Agric. Sci. Technol., 2(1), 31-41.

Assogba-Komlan F. et al., 2007. Pratiques culturales et teneur en éléments anti nutritionnels (nitrates et pesticides) du Solanum macrocarpum au sud du Bénin. Afr. J. Food Agric. Nutr. Dev., 7(4), 1-21.
Assogba-Komlan F., Yarou B.B., Mensah A. \& Simon S., 2012. Les légumes traditionnels dans la lutte contre les bioagresseurs des cultures maraichères : associations culturales avec le Tchayo (Ocimum gratissimum) et le Yantoto (Launaea taraxacifolia). Fiche technique. Cotonou, Bénin : INRAB.

Baidoo P.K., Mochiah M.B. \& Apusiga K., 2012. Onion as a pest control intercrop in organic cabbage (Brassica oleracea) production system in Ghana. Sustainable Agric. Res., 1(1), 36-41.

Bayaso I., Nahunnaro H. \& Gwary D.M., 2013. Effects of aqueous extract of Ricinus communis on radial growth of Alternaria solani. Afr. J. Agric., 8(37), 4541-4545.

Bokobana E.M. et al., 2014. Évaluation du potentiel insecticide et répulsif de l'huile essentielle de Cymbopogon schoenanthus (L.) Spreng. sur Aphis gossypii Glover (Homoptera : Aphididae), ravageur du cotonnier au Togo. Rev. Cames, 2(2), 48-55.

Bolou Bi Bolou A. et al., 2015. Inhibition de Sclerotium rolfsii Sacc. (Corticiaceae), agent causal de la pourriture du collet de la tige de la tomate (Solanaceae), par Xylopia aethiopica (Dunal) A.Rich. (Annonaceae) et Trichoderma sp. Eur. Sci. J., 11(12), 61-85.

Bordat D. \& Arvanitakis L., 2004. Arthropodes des cultures légumières d'Afrique de l'Ouest, centrale, Mayotte et Réunion. Montpellier, France : CIRAD/FLHOR.

Commission européenne, 2009. Règlement CE n 1107/2009 du Parlement européen et du Conseil du 21 octobre 2009 concernant la mise sur le marché des produits phytopharmaceutiques et abrogeant les directives 79/117/CEE et 91/414/CEE du Conseil. J. Off. Union Eur., 309(1), 1-50.

CSP, 2016. Liste globale pesticides autorisés par le comité sahélien des pesticides, http://www.reca-niger.org/IMG/ pdf/liste_pesticides_autorises_maraichage_fevrier2016. pdf, (20/9/2017).

Diabaté D., Gnago J.A., Koffi K. \& Tano Y., 2014. The effect of pesticides and aqueous extracts of Azadirachta indica (A.Juss.) and Jatropha carcus L. on Bemisia tabaci (Gennadius) (Homoptera: Aleyrididae) and Helicoverpa armigera (Hübner) (Lepidoptera: Noctuidae) found on tomato plants in Côte d'Ivoire. J. Appl. Biosci., 80, 71327143.

Doumbouya M. et al., 2012. Activités comparées in vitro de deux fongicides de synthèse et de deux huiles essentielles, sur des champignons telluriques des cultures maraichères en Côte d'Ivoire. J. Appl. Biosci., 50, 3520-3532.

Echereobia C.O., Okerere C.S. \& Emeaso K.C., 2010. Determination of repellence potentials of some aqueous plant extracts against okra flea beetles Podagrica uniforma. J. Biopesticides, 3(2), 505-507.

FAO, 2012. Growing greener cities in Africa. First status report on urban and peri-urban horticulture in Africa. Roma: FAO.

Fening K.O., Adama I. \& Tegbe R.E., 2014. On-farm evaluation of homemade pepper extract in the 
management of pests of cabbage, Brassica oleraceae L., and french beans, Phaseolus vulgaris L., in two agroecological zones in Ghana. Afr. Entomol., 22(3), 552-560.

Fotio D.\& Temwa A., 2012. Les biopesticides de plus en plus préconisés mais peu utilisés en agriculture de l'Afrique de l'Ouest et du Centre, http://www.cpac-cemac.org/ article_fr.php?IDActu=209, (20/09/2017).

Gnago J.A. et al., 2010. Efficacité des extraits de neem (Azadirachta indica) et de papayer (Carica papaya) dans la lutte contre les insectes ravageurs du gombo (Abelmoschus esculentus) et du chou (Brassica oleracea) en Côte d'Ivoire. Int. J. Biol. Chem. Sci., 4(4), 953966.

Grubben G.J.H. \& Denton O.A., 2004. Ressources végétales de l'Afrique tropicale. 2. Légumes. Wageningen, PaysBas : Fondation PROTA; Wageningen, Pays-Bas : CTA; Leiden, Pays-Bas : Backhuys Publishers.

Habou Z.A. et al., 2011. Insecticidal effect of Jatropha curcas oil on the aphid Aphis fabae (Hemiptera: Aphididae) and on the main insect pests associated with cowpeas (Vigna unguiculata) in Niger. Trop. Subtrop. Agroecosyst., 29(4), 225-229.

Houndété T.A. et al., 2010. Insecticide resistance in field populations of Bemisia tabaci (Hemiptera: Aleyrodidae) in West Africa. Pest Manage. Sci., 66(11), 1181-1185.

James B. et al., 2010. Gestion intégrée des nuisibles en production maraichère : guide pour les agents de vulgarisation en Afrique de l'Ouest. Ibadan, Nigéria: IITA.

Kambou G. \& Guissou I.P., 2011. Phytochemical composition and insecticidal effects of aqueous spice extracts on insect pests found on green beans (Phaseolus vulgaris) in Burkina Faso. Tropicultura, 29(4), 212217.

Kanda M. et al., 2009. Le maraichage périurbain à Lomé : pratiques culturales, risques sanitaires et dynamiques spatiales. Cah. Agric., 18(4), 356-363.

Kanda M. et al., 2013. Application des pesticides en agriculture maraichère au Togo. Vertig $O$, 13(1), 4-8.

Kanda M., Akpavi S. \& Wala K., 2014. Diversité des espèces cultivées et contraintes à la production en agriculture maraichère au Togo. Int. J. Biol. Chem. Sci., 8(1), 115127.

Kankam F. \& Sowley E.N.K., 2016. Evaluation of neem (Azadirachta indica L.) products for the control of rootknot nematode of chilli pepper (Capsicum annum L.). Arch. Phytopathol. Plant Prot., 49(5-6), 111-119.

Kolani L. et al., 2016. Investigation of insecticidal activity of blend of essential oil of Cymbopogon schoenanthus and neem oil on Plutella xylostella (Lepidoptera: Plutellidae). J. Essent. Oil Bearing Plants, 19(6), 14781486.

Laba B. et al., 2012. Efficacy of Cymbopogon schoenanthus L. Spreng (Poaceae) extracts on diamondback moth damaging cabbage. J. Biofertilizers Biopesticides, 3(3), 1-4.
Malézieux E. et al., 2009. Mixing plant species in cropping systems: concepts, tools and models. A review. Agron. Sustainable Dev., 29(1), 43-62.

Mochiah M., Banful B. \& Fening K., 2011. Botanicals for the management of insect pests in organic vegetable production. J. Entomol. Nematol., 3, 85-97.

MOMAGRI, 2016. Chiffres-clés de l'Agriculture, http:// www.momagri.org/FR/chiffres-cles-de-l-agriculture/ Avec-pres-de-40\%25-de-la-population-activemondiale-1-agriculture-est-le-premier-pourvoyeur-demplois-de-la-planete_1066.html, (20/09/2017).

Mondédji A.D. et al., 2014a. Evaluation of neem leavesbased preparations as insecticidal agents against the green peach aphid, Myzus persicae (Sternorrhyncha: Aphididae). Afr. J. Agric. Res., 9(13), 1086-1093.

Mondédji A.D. et al., 2014b. Efficacité d'extraits de feuilles de neem Azadirachta indica (Sapindale) sur Plutella xylostella (Lepidoptera: Plutellidae), Hellula undalis (Lepidoptera: Pyralidae) et Lipaphis erysimi (Hemiptera : Aphididae) du chou Brassica oleracea (Brassicaceae) dans une approche « Champ École Paysan » au Sud du Togo. Int. J. Biol. Chem. Sci., 8(5), 2286-2295.

Mondédji A.D. et al., 2015. Analyse de quelques aspects du système de production légumière et perception des producteurs de l'utilisation d'extraits botaniques dans la gestion des insectes ravageurs des cultures maraichères au Sud du Togo. Int. J. Biol. Chem. Sci., 9(1), 98107.

Nadio N.A. et al., 2015. Propriétés insecticides et répulsives de l'huile essentielle d'Ocimum sanctum L. envers Dysdercus voelkeri Schmidt (Heteroptera; Pyrrhocoridae). Rev. Cames, 3(2), 65-72.

Ngom S., Traore S., Thiam M.B. \& Anastasie M., 2012. Contamination des produits agricoles et de la nappe phréatique par les pesticides dans la zone des Niayes au Sénégal. Synthèse Rev. Sci. Technol., 25, 119-130.

Obi V.I. \& Barriuso-Vargas J.J., 2013. Effect of some botanicals on Colletotrichum destructivum O'Gara of cowpea. Afr. J. Microbiol. Res., 7(37), 4576-4581.

Odhiambo J.A.O., Gbewonyo W.S.K. \& Obeng-Ofori D., 2014. Insecticide use pattern and residue levels in cabbage (Brassica oleracea var capitata L.) within selected farms in Southern Ghana. J. Energy Nat. Resour. Manage., 1(1), 44-55.

Ogayo K.O. et al., 2015. Bioactivity of Leonotis nepetifolia and Ocimum gratissimum extracts in management of Tetranychus urticae Koch on French beans. Global J. Bio-Science Biotechnol., 4(3), 282-286.

Okereke V., Wokocha R. \& Godwin-Egein M.., 2007. Evalution of Trichoderma harzianum, some botanicals and a fungicide on Sclerotium wilt of potted tomato. Agric. J., 2(5), 555-558.

Sæthre M.-G. et al., 2011a. Aphids and their natural enemies in vegetable agroecosystems in Benin. Int. J. Trop. Insect Sci., 31(1-2), 103-117. 
Sæthre M.-G. et al., 2011b. Pesticide residues analysis of three vegetable crops for urban consumers in Benin. Bioforsk Rep., 6(40), 1-24.

Settle W. \& Garba M.H., 2011. Sustainable crop production intensification in the Senegal and Niger River basins of francophone West Africa. Int. J. Agric. Sustainability, 9(1), 171-185.

Settle W. et al., 2014. Reducing pesticide risks to farming communities: cotton farmer field schools in Mali. Philos. Trans. R. Soc. London, Ser. B, 369, 20120277.

Slotkin T.A., Stadler A., Skavicus S. \& Seidler F.J., 2016. Adolescents and adults differ in the immediate and longterm impact of nicotine administration and withdrawal on cardiac norepinephrine. Brain Res. Bull., 122, 71-75.

Son D., Somda I., Legreve A. \& Schiffers B., 2017. Pratiques phytosanitaires des producteurs de tomates du Burkina Faso et risques pour la santé et l'environnement. Cah. Agric., 26, 25005.

Sow G. et al., 2015. The use of Bacillus thuringiensis and neem alternation on Plutella xylostella (Lepidoptera: Plutellidae) and its effects on natural enemies in cabbage production. Acta Hortic., 1099, 391-398.

Tounou A.K. et al., 2011. Bio-insecticidal effects of plant extracts and oil emulsions of Ricinus communis L. (Malpighiales: Euphorbiaceae) on the diamondback, Plutella xylostella L. (Lepidoptera: Plutellidae) under laboratory and semi-field conditions. J. Appl. Biosci., 43, 2899-2914.
Traoré O. et al., 2015. Effet des extraits du thé de Gambie (Lippia multiflora Moldenk) et du neem (Azadirachta indica A.Juss.) sur Helicoverpa armigera et les thrips de la tomate (Lycopersicon esculentum Mill.). J. Appl. Biosci., 95, 8930-8936.

Wainwright H., Wanyamay C. \& Cherotich N., 2013. Biopesticides and their commercialisation in Africa. In: Proceedings of the First International Conference on Pesticidal Plants, 21-24 January 2013, Egerton University and ICIPE, Nairobi, Kenya, 189-191.

Yehouenou A. Pazou E. et al., 2006. Contamination of fish by organochlorine pesticide residues in the Ouémé River catchment in the Republic of Benin. Environ. Int., 32(5), 594-599.

Yolou F.I. et al., 2015. Maraichage en milieu urbain à Parakou au Nord-Bénin et sa rentabilité économique. Int. J. Innovation Sci. Res., 19(2), 290-302.

Zirihi G.N., Soro S., Kone D. \& Kouadio Y.J., 2008. Activité antifongique de l'extrait naturel de Combretum sp. in vitro sur 3 espèces fongiques telluriques des cultures de tomate en Côte d'Ivoire. Rev. Ivoir. Sci. Technol., 11, 131-142.

(68 réf.) 